\title{
Surveillance \& Society Diverted and Diverting Glances at Cameras: Playful and Tactical Approaches to Surveillance
} Opinion

\section{Justine Gangneux}

University of Glasgow, United Kingdom

j.gangneux.1@research.gla.ac.uk

\section{Introduction}

In line with Albrechtslund and Dubbeld (2005) and their call for a new direction in Surveillance Studies, this paper discusses the overlapping of surveillance, art and entertainment. Surveillance has been mostly considered through social control theories (e.g. social sorting of youth or homeless), criminology (e.g. surveillance technologies as tools to prevent crime) or as an infringement of privacy. Although these studies are essential, they neglect a dimension of surveillance that is not only top-down or worrying but also can be participatory, bottom-up, playful or/and entertaining. As Albrechtslund and Dubbeld have highlighted, surveillance-enabling technologies also encompass 'fun features and entertainment values' (2005: 216). Drawing on this new direction in Surveillance Studies, this paper focuses on the interplay between watcher and watched and the possibility of challenging surveillance's processes through games, artistic, tactical or/and playful motives.

Play and games within this framework relate to an active (re)appropriation of surveillant hegemonic values and sometimes directly of surveillant means. Playing with and elaborating these values and means demonstrates both acceptance (sometimes reinforcing surveillance processes) and/or contestation by creating a space of negotiation (and therefore the possibility of resistance). This paper discusses, using several examples, the line between art, entertainment, and resistance that leaves a wider margin to interact, assess, and respond creatively to surveillance processes.

\section{Diverted and Diverting Surveillance: Who is Watching Whom?}

Surveillance is largely embedded within our contemporary culture (i.e. films, television, video games, advertising, and art) and therefore it has transformed our ways of seeing, watching, and being seen. Finn argues that surveillance has become, in our highly visual Western society, not only a way of seeing, but also an aesthetic, a rhetoric, and a call for participation in public life (2012: 65). Thus, surveillance is integrated in our everyday within an urban imaginary (vision), imagination (perception), and common imagery (aesthetics) that have become normalised.

Various artists have focused their works or performances around the rise of a 'surveillance society' within the last decades. ${ }^{1}$ For instance, Manu Luksch in her work Faceless used CCTV footage to create a

\footnotetext{
${ }^{1}$ See the 2010 Special Issue of Surveillance \& Society, 'Surveillance, Performance and New Media Art' 7(2). 
disturbing dystopian film (see Zeilinger 2012, but also the CCTV Film Makers Manifesto ${ }^{2}$ and video sniffing techniques). The Surveillance Camera Players (SCP) have performed famous plays and novels, such as Alfred Jarry's Ubu Roi or Samuel Beckett's Waiting for Godot, ${ }^{3}$ playfully and creatively reappropriating the surveillance means in front of both the surveillant gaze ${ }^{4}$ and passers-by. More recently, the artist collective !Mediengruppe Bitnik, in their performance entitled 'Surveillance Chess' (see this issue) has hijacked surveillance camera signals to ask the CCTV operator to play chess. ${ }^{5}$ Drawing on the pioneer artistic experiment conducted by Denis Beaubois in Sydney in 1996, In the event of Amnesia, the city will recall, ${ }^{6}$ wherein Beaubois used written placards to establish a dialogue with the surveillance camera operators in Sydney, artistic performances divert surveillance processes both by displacing them and by amusing an audience. In Beaubois and others' work, the camera itself becomes part of the performance, as well as its subject and condition of possibility (if the surveillance camera were not there; Beaubois would not have been able to create his piece in the first place). It normalises surveillance as being part of the urban environment and questions it by playing with cameras and pointing them out: Why is the camera here? Who is watching? Is it acceptable or not to play with a surveillance camera? It also highlights ambiguities between surveillance, art, and entertainment where being under scrutiny colludes with the pleasure of being watched. Indeed these performances play on a dialectical relationship between 'a voyeuristic fascination in looking and an exhibitionist fascination in being seen' (Koskela 2009: 156).

These different works seek to upset the normalised way of looking at surveillance by challenging the boundary between surveillance and entertainment. They can be understood as an inventive, often striking, re-appropriation of surveillant means. They are meant to be looked at, sometimes even set up as a stage (e.g. the SCP) or as a spectacle, and to distort surveillant means either materially (i.e. the use of CCTV footage or cameras themselves) or symbolically within a bottom-up perspective. However these few examples (and there are many others) remain attached to the artistic field, staring at closed circuit television surveillance systems in other enclosed time-spaces, whether in a museum, a gallery, online, or during a performance.

\section{Détournement of the Surveillant Gaze}

These artistic performances have been influenced by the International Situationist movement and the practice of 'détournement' (Debord and Wolman 1956) also known as 'situationist pranks'. By turning the means of surveillance against itself, artists use a form of subversive pranks where monitoring becomes a parody of itself, a mimicry that appears more real than the original (due to its new visibility). However, these pranks are not only amusing but serve more serious aims:

Such parodistic methods have often been used to obtain comical effects. But such humour is the result of contradictions within a condition whose existence is taken for granted. Such contradictions don't make us laugh. It is thus necessary to envisage a parodic-serious stage where the accumulation of detourned elements, far from aiming to arouse indignation or laughter by alluding to some original work, will express our indifference toward a meaningless and forgotten original.

(Debord and Wolman 1956: 2)

\footnotetext{
${ }^{2}$ Available at http://www.ambienttv.net/content/?q=dpamanifesto

${ }^{3}$ See full listing of their scripts for performances in front of surveillance cameras at http://www.notbored.org/scp-scripts.html

${ }^{4}$ See the Surveillance Camera Players' webpage at http://www.notbored.org/the-scp.html

${ }^{5}$ See the Surveillance Chess website at http://wwwwwwwwwwwwwwwwwwwwww.bitnik.org/s/ and Bitnik in this issue.

${ }^{6}$ See Denis Beaubois's webpage at http://www.denisbeaubois.com/Amnesia/In $\% 20$ the $\% 20$ event $\% 20$ of $\% 20$ Amnesia $\% 20$ copy $\% 202 . h t m l$
} 
In other words, the 'détournement' of surveillance processes put an emphasis on our indifference and tacit consent to the 'meaningless and forgotten original' (i.e. the surveillance cameras). In this way, détournements are not only witty pleasantries in order to provide amusement, but also have to be comprehended within the idea of 'parodic-serious stage' where they force us to pay attention and look at the subject of the prank itself. Through their own parody, surveillance-enabling technologies are critically staged as a normal part of everyday life. These 'pranks' are ambiguous, both denouncing and entertaining, serious and casual, conservative and critical. But by diverting public's eyes and surveillance technologies, they offer a space of negotiations, resistance, and reflections on processes that are usually taken for granted and/or invisible.

The Dutch art collective Front $404^{7}$ celebrated the 110th birthday of George Orwell on the 25th of June, 2013 by decorating surveillance cameras with party hats in the city centre of Utrecht. At first sight, this can be seen just as a humorous act for the occasion or as a pretext to denounce generally the rise of a surveillance society. However by unmasking cameras with these incongruous and colourful accessories, it challenges subjects of the prank themselves (i.e. the cameras). By diverting the city-dwellers' eyes, that is, catching their attention and encouraging them to look at surveillance cameras, the performance raises a new awareness of the amount of surveillance in Utrecht and intrinsically defies it.

\section{Surveillance: A Serious Joke?}

Humour and détournement act differently because they are meant to be outside the artistic field (even though most of the time they are performed by artists) and raise our awareness where 'the joke is on us'. These small acts, such as the Orwell Birthday party, are situated within a humorous register of interpretation that makes critique acceptable and surveillance laughable. By dressing cameras with party hats (even without knowing that it is for the occasion of George Orwell's birthday), Front404 violates implicit norms of ubiquity and seriousness in these systems and makes them instead visible and risible. McGraw and Warren (2010) have shown that humour can arise as an adaptive response to 'benign violations' i.e. something that upsets people's perceptions of 'how the world ought to be' (2010: 1142). According to them, it becomes benign due to either the presence of another norm suggesting that the situation is acceptable (e.g. CCTV cameras prevent crime), the weak commitment to the violated norm (e.g. indifference of being surveilled), and/or a psychological distance from the violation (e.g. surveillance does not concern me as 'I have nothing to hide').

Such small acts ought to be comprehended as playful 'tactics' rather than as strategic and frontal resistance against a given phenomenon (in this case surveillance). But nonetheless, they participate to challenge it. de Certeau (1984) defines 'tactics' as following:

Tactic is the inventive employment of possibilities within strategic circumstances: disguise, surprise, discretion, secrecy, wit, play, bluff and so on. Crucially tactics don't operate outside a strategy that they can confront, to do this would require a counterstrategy, and they are in the ambiguous position of being inside but 'other'.

(de Certeau 1984: 159)

Play, and playfulness, can be understood as tactics in de Certeau's terms. 'Being playful' with surveillance processes needs to be viewed as an interaction that can trigger acceptance and/or protest. It is an unsettled experimentation in 'doing', situated in a place and time. Furthermore, these tactics of defiance can be hidden within the register of playfulness and games. Due to the fact that 'play' is seen primarily as 'the act of engaging in activity for enjoyment and recreation rather than a serious or practical purpose' (Oxford Dictionary), it is a powerful locus for entertainment but also for resistance. In this way, tactics belong to

\footnotetext{
${ }^{7}$ See their website at http://front $404 . c 0 m /$
} 
the realm of play and games in which disguise, surprise, wit, and bluff are as much of an entertainment as ordinary means to evade, divert, and/or mock something that upset 'how the world ought to be'. It can also relate tightly to defiance based on this idea of playing within the system. Thus, defiance, instead of being seen as a purposeful strategy against the dominant gaze and power, can be seen as and pursued through playful and interactive tactics within surveillance processes.

In everyday life, tactics of resistance or defiance can be found in a common blasé attitude to surveillance and take the forms of humour and mockery (i.e. acknowledgement of the inappropriate character of surveillance through jokes). In this regard, surveillance can be comprehended literally as a serious joke. Paradoxically derisive ways of talking about surveillance take part in a wider logic of legitimisation and acceptance. For instance, the common featuring of a Big Brother-like world in everyday jokes and its humorous dramatisation regarding futuristic outcomes creates grounds for normalisation of surveillance and contribution to its reinforcement. Jokes can reflect on the seriousness of the topic where there is a permanent renegotiation of the acceptable (i.e. the norm and its benign violation).

\section{Playful Sousveillance?}

Surveillance is at the intersection between individuals and their everyday environments such as their urban spaces and workplaces. However, surveillance is not only a top-down phenomenon always passively accepted by individuals, but rather a place of negotiation, interaction, and interplay. The Front404's performance brings a new dimension to the dominant top-down perspective on surveillance by uncovering inconspicuous cameras and shedding light on them. In doing so, it raises a new awareness of the number of surveillance cameras and provides a form of bottom-up surveillance by putting them under scrutiny. This playful protest can be encompassed within the idea of sousveillance (inverse surveillance) coined by Mann and colleagues (Mann, Nolan and Wellman 2003). Sousveillance draws on 'reflectionism' that is 'appropriating tools of social controllers and resituating the tools in a disorientating manner' (Mann et al. 2003). In this way, Front 404 appropriated the tools of the social controllers, (i.e. surveillance cameras), and re-contextualised them in an unexpected way.

Humorous and playful moves within surveillance have been facilitated and exacerbated through the widespread development of digital media. Indeed digital technologies and social media enable artists but also ordinary people to shoot back, look and stare at the surveillor, both playing off the other. It could also be said that late modern conditions (Giddens 1991; Beck 1992) have provided more grounds for satiric responses. Part of this is the lack of credible alternatives to a surveillance society. If the public feels that there is nothing that they can do about the rise of a surveillance state, at least they can joke and be sarcastic about it.

The 2013 protest against the rise of CCTV cameras across Germany that took the form of a reality street game known as "Cam-Over" ${ }^{8}$ in Berlin is a striking example of the intertwined motives of play and resistance. The game was largely diffused through the internet (especially YouTube). Protesters-gamers were supposed to destroy as many CCTV cameras as possible in different ways while recording it. ${ }^{9}$ The only requirement was to 'be aware of internet-safety' or, in other words, of online surveillance. This example shows that resistance, art and play are not binaries but embedded within ambiguous dynamics, including: political protest against the growth of surveillance cameras in Berlin; defiance against the police' participation in the game to gain rewards on social media or within social relationships; and sousveillance, to name few of possible incentives. It reflects practical (short-term gains), social, entertaining, personal, political, and/or ethical aims, although most of the time it is not necessary claimed as such.

${ }^{8}$ See The Guardian at http://www.theguardian.com/theguardian/shortcuts/2013/jan/25/game-destroy-cctv-cameras-berlin

${ }^{9}$ See Guide to CCTV Destruction at http://www.schnews.org.uk/diyguide/guidetoclosedcircuittelevisioncctvdestruction.htm 
Without trashing cameras, active or direct sousveillance, such as wearing computing devices for data collection (e.g. copwatching), can be seen as frightening and risky. Protest or political moves can be disguised and located within playful or humorous registers, avoiding a frontal confrontation against the surveillance system. Furthermore frontal resistance such as Cam-Over is easily assimilated with vandalism or terrorism and therefore it is immediately extracted from the discussion of normal politics to fall into discourses of panics and securitisation (Buzan, Waever and de Wilde 1998). Therefore, playful, satiric, and tactical approaches can be seen as a means, although not all are, of everyday resistance and responses to surveillance.

\section{Concluding thoughts}

Surveillance has been largely studied within sociology, criminology and security studies all extensively incorporating the Panopticon imaginary of Jeremy Bentham. The call of Albrechtslund and Dubbeld for a new direction in Surveillance Studies reflects recent trends to embrace surveillance regarding empowerment, participation, entertainment, and art (Albrechtslund 2008; McGrath 2004; Martin, van Brakel and Bernhard 2009; Koskela 2006, 2009). Surveillance is ubiquitous and tightly embedded within our contemporary culture. We interact with it in everyday life for a range of different reasons; whether it is by convenience, conviction, fear, entertainment, pleasure, voyeurism, or boredom. As a reflection of this, our interactions with surveillance processes are not only a simplistic top-down compliance but play on a wider range of social, personal, artistic, and entertaining motives that engage within them. By being an integral part of late modern Western culture, surveillance promotes responses that are more complex than an acceptance/resistance binary. Artists and ordinary people engage with surveillance in the practice of everyday life (de Certeau 1984) altering, noticing, playing, appropriating, questioning, and/or complying with it. The interplay between watchers and watched is not novel, but this is reinforced by the diffusion of digital technologies as well as by the embodiment of a surveillant assemblage (Haggerty and Ericson 2000 ) in everyday life. Within this dialectical interaction (top-down and bottom up), play, games, and the use of humorous registers can be a powerful locus for defiance and resistance to surveillance as well as a benign form of normalising its processes.

\section{References}

Albrechtslund, A. and L. Dubbeld. 2005. The Plays and Arts of Surveillance: Studying Surveillance as Entertainment. Surveillance \& Society 3(2/3): 216-221.

Albrechtslund, A. 2008. Online Social Networking as a Practice Based on Participatory Surveillance. First Monday 13(3).

Beck, U. 1992. Risk Society: Towards a New Modernity. London: SAGE Publications.

Buzan, B., O. Weaver and J. de Wilde. 1998. Security: A New Framework for Analysis. Boulder, CO: Lynne Rienner.

Debord, G. and G. Wolman. 1956/2006. A User's Guide to Détournement. Originally appeared in Les Lèvres Nues \#8. Translation by K. Knabb. Available online at: http://www.bopsecrets.org/SI/detourn.htm\#1

de Certeau, M. 1984. The Practice of Everyday Life. Berkeley: University of California Press.

Finn, J. 2012. Seeing Surveillantly: Surveillance as Social Practice. In Eyes Everywhere: The Global Growth of Camera Surveillance, edited by A. Doyle, R. Lippert and D. Lyon. Oxon: Routledge.

Giddens, A. 1991. Modernity and Self-Identity: Self and Society in the Late Modern Age. Stanford: Stanford Univ. Press.

Haggerty, K.D. and R.V. Ericson. 2000. The Surveillant Assemblage. British Journal of Sociology 51(4): 605-622.

Koskela, H. 2009. Hijacking Surveillance? In Technologies of InSecurity: The Surveillance of Everyday Life, edited by K. F. Aas, H. O. Gundhus, and H. M Lomell. Oxon: Routledge-Cavendish.

Koskela, H. 2006. The Other Side of Surveillance: Webcams, Power and Agency. In Theorizing Surveillance: The Panopticon and Beyond, edited by D. Lyon. Cullompton: Willan Publishing.

Mann, S., J. Nolan, and B. Wellman. 2003. Sousveillance: Inventing and Using Wearable Computing Devices for Data Collection in Surveillance Environments. Surveillance \& Society 1(3): 331- 355.

Martin, A.K., R.E. van Brakel and D.J. Bernhard. 2009. Understanding Resistance to Digital Surveillance: Towards a Multidisciplinary, Multi-actor Framework. Surveillance \& Society 6(3): 213-232.

McGrath, J. 2004. Loving Big Brother: Performance, Privacy and Surveillance Space. London: Routledge.

McGraw, A.P. and C. Warren. 2010. Benign Violations: Making Immoral Behavior Funny. Psychological Science 21(8): 1141-9.

Zeilinger, M. 2012. Appropriation and the Authoring Function of Camera Surveillance in Manu Luksch's Faceless. In Eyes Everywhere: The Global Growth of Camera Surveillance, edited by A. Doyle, R. Lippert and D. Lyon. Oxon: Routledge. 